\title{
Care competencies in adolescents: Development of a new measure and relationships with well-being
}

\author{
Nguyen Phuoc Cat Tuong ${ }^{1,2}$ (D) $\cdot$ Wim Beyers ${ }^{3} \cdot$ Martin Valcke $^{4}$ \\ Published online: 9 January 2020 \\ (C) Springer Science+Business Media, LLC, part of Springer Nature 2020
}

\begin{abstract}
Worldwide, we observe an increasing focus on fostering well-being in adolescents. This is reflected in growing research in the field of care. However, empirical research is lacking that focuses on the relationship between components of care: receiving care, self-care and extending care. This lack of research is mirrored in the lack of valid measures for assessing care competencies in educational contexts. The present research, therefore, has four goals: 1) to create a valid and reliable scale assessing levels of care competencies based on the multifaceted and multidimensional concept of care; 2) to explore the relationship between sociodemographic characteristics and care competencies in adolescents; 3 ) to examine the psychological outcomes associated with different levels of care competencies in adolescents; 4) to explore the interaction of the three care dimensions in predicting adolescents' well-being. Based on data from 742 adolescents, a reliable and valid scale could be developed with six subscales: Receiving care, self-care and extending care, with each of them falling apart in care competencies and care failures. Gender, age and academic achievement were related to care competencies/failures. Findings support the link between adolescents' well-being and care competencies/failures. These results have implications for promoting adolescents' well-being through school-based care-cultivation programs.
\end{abstract}

Keywords Adolescents $\cdot$ Care competencies $\cdot$ Well-being $\cdot$ Scale development

Adolescence is a developmental period characterized by rapidly transformative biological, neurological, psychological and social changes (Layden and Shale 2012). These dynamic transitions may place them at risk of ill-being (Bakar and Sidek 2013). Although the majority of adolescents report a

Nguyen Phuoc Cat Tuong

CatTg.Nguyh@Ugent.be

Wim Beyers

Wim.Beyers@Ugent.be

Martin Valcke

Martin.Valcke@Ugent.be

1 Faculty of Psychology and Educational Sciences - Department of Developmental Personality and Social Psychology, Ghent University, Belgium, Henri Dunantlaan 2, 9000 Ghent, Belgium

2 Department of Psychology and Education, Hue University of Education-Hue University, 34 Le Loi St, Hue 49000, Vietnam

3 Faculty of Psychology and Educational Sciences - Department of Developmental, Personality and Social Psychology, Ghent University, Henri Dunantlaan 2, 9000 Ghent, Belgium

4 Faculty of Psychology and Educational Sciences - Department of Educational Studies, Ghent University, Henri Dunantlaan 2, 9000 Ghent, Belgium high and stable level of well-being (Birkeland et al. 2012), a minority of young people report a lower level of well-being and mirror a number of subjective mental health worries. Around the world, about $20 \%$ of adolescents experience a behavioral problem or mental disorder (Kessler et al. 2005). This might be an under-estimation since adolescent's mental health problems are often not recognized, untreated and/or not reported in research (Sourander et al. 2004). Ill-being not only has damaging effects on individual adolescents in terms of social, intellectual and emotional development but also impedes the society in its social security, sustainable development, healthcare cost and productivity (WHO 2016). A call for accelerated actions to improve the well-being of adolescents is, therefore, globally put forward (WHO 2019).

The opportunity to close the youth well-being gap is, however, real. The field of care has made significant progress in understanding the role of care competencies in promoting individuals' well-being (Mind and Life Institue 2014). Accordingly, school-based programs which directly focus on enhancing care competencies for adolescents should be conducted (Noddings 2004). In this context, measuring and analyzing the care competencies of adolescents and their relationships with well-being may be a prerequisite for developing evidence-based interventions for adolescents. However, while 
there are good theoretical reasons to believe that adolescents' well-being depends on the quality and quantity of care that they are capable to receive from others, develop for themselves and extend to those around them, the construct of care has not yet been examined empirically. A key reason for this is the lack of psychometrically sound and age-appropriate measures to study care competencies in adolescents. Based on a literature review of the available empirically validated measures, MLI (Mind and Life Institute 2014) concluded no scale is yet available to measure care competencies in the adolescent population. This suggests future research needs to develop a valid and reliable measure of care competencies in adolescents; and based on this, empirically examine the well-being outcomes associated with different level of adolescents' care competencies.

\section{What Is Care? Toward an Integrated Definition}

"The concept 'care' is commonplace in lay and sociological discourses but is hardly uniformly defined" (Thomas 1993, p. 649). Examination of the concept of care results in the identification of an overlapping set of perspectives (Morse et al. 1990). Nevertheless, most authors agree on the nature of care as either a feeling state (emotion, affection, love), caring about someone, or an activity state (work, tasks, labors), caring for someone (Morse et al. 1990). As such, care can be construed as both an attitude and an action. Held (2006) puts this as follows: "All care involves attentiveness, sensitivity and respond to needs" (p. 39). And Gastmans (2006) confirms: "Good care demands more than just good intention; good care ... is a practice of combining activities, attitudes, and knowledge of the situation" (p.137). Care, therefore, can also be approached as a competency since it combines knowledge, skills, attitudes and behavior, making an individual able to perform a certain task at a given level (Blömeke et al. 2015). As such, care can be structured following its cognitive, affective and behavioral competency facets: (1) being aware of and apprehending an individual's current situation or needs (cognitive); (2) responding sympathetically and empathetically to those needs (affective); and (3) acting to meet the needs of an individual (behavioral).

Next to being multi-faceted, care is also a multi-dimensional concept. Looking at the actor-dimension, care rather can be characterized as an aspect of social relations than as an individual's trait or behavior (Held 2006). This explains why Noddings (1984) stresses that - in a reciprocal relationship between two human beings - care implies both a person one-caring and a person cared-for. Care cannot be sustained if a caring person fails being attentive and/or refuses to respond, or if the person being cared-for is unable or unwilling to receive the care of others (Noddings 1984). This multi-dimensional nature helps enriching the concept of care with a receiving care and extending care dimension. Next, besides receiving care and extending care, also self-care is getting accepted as an indispensable dimension. Selfcare implies monitoring of one's own well-being, growth, and competencies in order to competently and successfully engage in a caring relationship (Hamington and Sander-Staudt 2011). It is essential to reflect on our own needs and ensure that oneself is not subsumed in a caring relationship (Tronto 1993).

Taken together, the MLI (Mind and Life Institue 2014) reflects the relational nature of care through a framework of three interdependent dimensions of care: receiving care, selfcare and extending care. Building on the multifaceted conception of care, 'receiving care' can be seen as the competencies to be aware of and receptive to (1) others' noticing to your own situation/needs (cognitive); (2) others' empathetic feelings to your own situation/needs (affective); (3) others' actions to meet your own needs (behavioral). 'Self-care' is regarded as the competencies to (1) notice and understand the needs of yourself (cognitive); (2) empathetically react to and accept your own situation/needs (affective); (3) act to meet you own needs (behavioral). 'Extending care' can be described as the competencies to (1) notice and understand others' situation/needs (cognitive); (2) empathetically react to and accept others 'situation/needs (affective); (3) act to meet others' needs (behavioral). From this perspective, empathy - the capacity to place oneself in another's position (Bellet and Maloney 1991) - can be seen as part of the cognitive and affective facets of extending care. Mindfulness can be regarded as a cognitive and affective practice of self-care by which an individual becomes aware of and accepts painful experiences in a balanced and non-judgmental way (Brown and Ryan 2003). Especially, compassion, the desire and will to care for and to help alleviate one's suffering (Gilbert et al. 2017), can be regarded as one typical, critical manifestation of extending care. In general, the above working definitions suggest that care is connected to other constructs such as social support, empathy, altruism, prosocial behavior, mindfulness and compassion (Nguyen et al. 2019).

\section{What Is Well-Being?}

Despite the available body of research, there is no consensus on the definition of well-being. Two approaches can be adopted in defining this concept: hedonism versus eudaimonism. The hedonic approach is based on the notion that increased pleasure and a decrease in pain lead to higher wellbeing (Ryan and Deci 2001). Accordingly, subjective wellbeing is defined as "the pursuit of happiness and a pleasant life" (Chen et al. 2012; p.1034) or the total of positive affect, negative affect and life satisfaction (Grenville-Cleave 2012). Alternatively, the eudaimonic approach is based on the premise that people attain a higher well-being when they 
experience the meaningfulness of life, challenges, and personal growth (Ryan and Deci 2001). Well-being within this approach is defined as psychological well-being (Chen et al. 2012). Burn (2016) stated that "psychological well-being refers to inter- and intra-individual levels of positive functioning that can include one's relatedness with others and self-referent attitudes that include one's sense of mastery and personal growth" (p.1). Taken together, well-being is about: (1) the presence of positive emotions and moods (e.g., contentment, happiness); (2) the absence of negative emotions (e.g., stress, depression, anxiety); and (3) satisfaction with life, fulfillment and positive functioning. Based on this comprehensive perspective, though correlated, well-being is not direct opposites of ill-being, which is related to pervasive negative affects and functioning (Ryff et al. 2006). Specifically, those with low level of well-being would not be expected to show high level of ill-being.

\section{Care Competencies and Well-Being in Adolescents}

Previous cross-sectional as well as longitudinal studies affirm the important role of care competencies for adolescents' wellbeing. Regarding the receiving care dimension, several studies (e.g., Bal et al. 2003; Danielsen et al. 2009) revealed that social support perceived and received from families, teachers or classmates increased adolescents' life satisfaction and positive affect and decreased their depressive symptomatology and negative affect. With respect to the self-care dimension, studies by Bluth and Blanton (2015) and Neff and McGehee (2010) showed that mindfulness and self-compassion were significantly related to all measured dimensions of wellbeing (reduced negative affect, perceived stress, anxiety and depression; increased positive affect and life satisfaction). Regarding the extending care dimension, previous studies showed that adolescents who performed prosocial and altruistic acts experienced significantly higher well-being (Layous et al. 2012; Pareek and Jain 2012).

As a trainable resource, care competencies may provide a valuable tool for promoting overall well-being (Jazaieri et al. 2017). Several intervention studies showed how cognitive and affective empathy training reduced bullying (e.g., Sakofsky 2009), cyberbullying (e.g., Schultze-Krumbholz et al. 2016) and aggressive behavior of adolescents (e.g., Vaziri and Lotfi Azimi 2012). Besides, stronger mindfulness, compassion and self-compassion interventions resulted in lower negative affect and higher happiness, as well as more positive functioning of adolescents (Bluth and Eisenlohr-Moul 2017; Edwards et al. 2014; Ferrari et al. 2019). More significantly, schoolbased care-cultivation programs confirmed the impact of a 'pedagogy of care' on adolescents' well-being (Battistich et al. 1997; Chang 2008).
Moreover, as mentioned, care dimensions are interdependent; thus, they might interact with each other to affect individuals' well-being (Mind and Life Institue 2014). For example, extending care may be related to higher well-being only when it flows naturally out of the other components: receiving care and developing self-care; if not, it may lead to compassion fatigue or empathy distress (Mind and Life Institue 2014). Empirically, findings in the study by Cosley et al. (2010) revealed that the combination of received social support and compassion for others predicted decreases in stress level. A cross-cultural multi-study by Hermanto et al. (2016) showed that the ability to receive compassion from others buffers the depressogenic effect of self-criticism.

In general, the number of empirically validated studies related to the relationship between care competencies and wellbeing in adolescents tends to increase. However, to our knowledge, no empirical studies have directly and simultaneously examined the relationship between all three dimensions of care competencies and well-being as well as their interactions in predicting well-being in adolescents.

\section{The Present Study}

Based on the conceptualization of care competencies and research evidence cited above, the present research, therefore aimed to create a valid and reliable scale reflecting the multidimensional nature of care and assessing these care-competencies. Further, we wanted to empirically test the following hypotheses: (1) socio-demographic characteristics will be significantly related to care competencies in adolescents; (2) care competencies will be positively correlated with indicators of well-being and negatively correlated with indicators of illbeing in adolescents; (3) the three care dimensions will significantly interact with each other in predicting well-being in adolescents.

\section{Methods}

\section{Participants and Procedure}

Adolescents, aged 13 to 18 years were recruited from two junior high schools and two high schools in Hue City, Vietnam. Active informed consent for school participation was obtained through the directorate of the Education and Training Department of Hue City in line with formal regulations. A set of questionnaires to assess care competencies and well-being was administered to 813 students. On the first page of the questionnaire participants signed an active informed consent. Administration took place during school time in regular class groups of 40 to 45 students, taking a maximum $45 \mathrm{~min}$. Prior to data collection, survey proctors and teachers 
were provided with the aims of the survey, an introduction to the concept of care and the instructions for administration. Next, teachers were responsible for the administration in their own class with the support of survey proctors. The first author of this article was available to answer questions raised by participants.

Prior to data analysis, a quality screening was set up. In cases of conflicting responses, too many missing items or strange answer patterns, tests were excluded. This resulted in 742 valid responses from 416 female and 326 male adolescents ( $M$ age $=14.63 ; S D=1.08)$ to be included in the statistical analysis (91.3\%). Demographic data of the participants are summarized in Table 1. Within this sample, only $0.3 \%$ of the data were missing. Little's (1988) test, which tests the assumption of Missing Completely at Random (MCAR) versus Missing at Random (MAR) revealed that data were MCAR (normed $\chi^{2}=1.07$ ). Therefore, in all further analyses we relied on the Full Information Maximum Likelihood approach (Enders 2001) and $N=742$.

\section{Measures}

Care Competencies To measure adolescents' care competencies, 36 potential scale items were first generated by the researchers, building on a literature review (Nguyen et al. 2019) and through brainstorming. In line with the three theoretical dimensions, three subscales were put forward: receiving care, self-care and extending care. Each subscale was composed of 12 items with 6 positively worded statements and 6 negatively worded statements, tapping into the three facets of care (cognitive, affective and behavioral facets). The use of an equal number of negative and positive worded items is recommended by several researchers to make measures more valid (e.g., Baumgartner and Steenkamp 2001; Podsakoff et al. 2003). Sample items are presented in Table 3. Respondents scored each item on a Likert scale from 1 totally untrue about me to 6 totally true of me. The validity and reliability of this Care Competencies Questionnaire for Adolescents (CCQA) is being presented in the first part of the Results section.

Well-Being Well-being of adolescents was measured using three validated scales. First, the self-rated version of the Strengths and Difficulties Questionnaire (SDQ- Goodman 1997) was used to assess emotional and behavioral disorders of adolescents. The SDQ is predictive of psychiatric diagnoses in many developed and developing countries, including Vietnam (Tran 2006). It is composed of 25 items, of which 20 items were used in this study, covering four areas of adolescents' difficulties: Emotional symptoms (5 items. e.g., Often unhappy, depressed or tearful), conduct problems (5 items; e.g., Often fights with other children), hyperactivity/ inattention (5 items; e.g. Thinks things out before acting), and peer problems (5 items; e.g., Gets along better with
Table 1 Sociodemographic Characteristics of the Participants

\begin{tabular}{|c|c|c|}
\hline & $n$ & $\%$ \\
\hline \multicolumn{3}{|l|}{ Areas } \\
\hline Rural & 408 & 55.0 \\
\hline Urban & 334 & 45.0 \\
\hline \multicolumn{3}{|l|}{ Family structure } \\
\hline Parents live together & 668 & 89.4 \\
\hline Parents are divorced & 32 & 4.3 \\
\hline One parent is deceased & 36 & 4.9 \\
\hline Others & 11 & 1.5 \\
\hline \multicolumn{3}{|l|}{ Father } \\
\hline Father is biological father & 668 & 90.0 \\
\hline Father is stepfather & 4 & 0.5 \\
\hline Father is foster father & 4 & 0.5 \\
\hline Others & 66 & 8.9 \\
\hline \multicolumn{3}{|l|}{ Mother } \\
\hline Mother is biological mother & 695 & 93.7 \\
\hline Mother is stepmother & 7 & 0.9 \\
\hline Mother is mother & 6 & 0.8 \\
\hline Others & 34 & 4.6 \\
\hline \multicolumn{3}{|l|}{ Family size } \\
\hline One child & 40 & 5.4 \\
\hline Two children & 226 & 30.5 \\
\hline Three children & 252 & 34.0 \\
\hline More than 3 children & 224 & 30.2 \\
\hline \multicolumn{3}{|l|}{ Family economic status } \\
\hline Rich & 127 & 17.1 \\
\hline Average & 543 & 73.2 \\
\hline Poor & 58 & 7.8 \\
\hline Very poor & 14 & 1.9 \\
\hline \multicolumn{3}{|l|}{ Academic achievement (GPA) } \\
\hline Good & 146 & 19.7 \\
\hline Fair & 252 & 34.0 \\
\hline Average & 332 & 44.7 \\
\hline Poor & 12 & 1.6 \\
\hline
\end{tabular}

adults). These items were rated on a 3-point Likert scale $(0=$ not true $; 1=$ somewhat true $; 2=$ certainly true $)$. In line with the manual, a total difficulty score was calculated based on all 20 items (Goodman and Goodman 2012). Cronbach's alpha in our data was .72. Second, the Perceived Stress Scale (PSS; Cohen and Williamson 1988) was used to measure adolescents' general level of stress during the past month (e.g., In the past month, how often have you been upset because of something that happened unexpectedly?). Answers were rated on a Likert-scale ranging from 0 never to 4 very often. In Vietnam, this scale was underscored by Nguyen and Nguyen (2012) with satisfactory reliability (alpha $=.71$ ). In the present study, to obtain acceptable Cronbach's alpha, we had to leave out four positive items with low item-total correlations. 
Finally, six negative worded items were retained with a Cronbach's alpha of .64. Third, the Satisfaction with Life Scale (SWLS, Diener et al. 1985) was used to assess overall life satisfaction of adolescents. The five scale items are phrased positively (e.g., In most ways my life is close to ideal) and were answered using a 7-point Likert-rating (1 strongly disagree to 7 strongly agree). In Vietnam, this scale was validated in medical university students by Nguyen and Nguyen (2012) who reported satisfactory reliability (alpha $=.75$ ). In the present study, Cronbach's alpha was found to be acceptable (.66).

\section{Data Analysis}

In order to test the construct validity of the CCQA, an initial exploratory factor analysis (EFA) was performed with principal components extraction and promax rotation. Based on the EFA-findings, the factor structure was checked via confirmatory factor analysis (CFA), using robust maximum likelihood estimation (MLR) given non-normality of most item scores. Items not fitting the measurement model due to low factor loadings $(<.30)$ were removed from the model, but keeping in mind the three facets of care (cognitive, affective and behavioral) to be covered in each subscale. The following fit indices were used: normed $\chi^{2}\left(\chi^{2} / d f\right)$, comparative fit index (CFI), standardized root-mean-square residual (SRMR), and root mean square error of approximation (RMSEA). The following benchmark fit values were applied: normed $\chi^{2} \leq 3$, RMSEA $<.05$ ( $<.08$ is acceptable), CFI $>.95$ ( $>.90$ is acceptable), and $S R M R<.05$ ( $<.08$ is acceptable) (Hu and Bentler 1999; Kline 2011). In order to test convergent validity, Pearson correlations were calculated between the factors.

Reliability of the scale scores was measured by calculating the internal consistency coefficient alpha (Cronbach 1951). Going beyond Cronbach's alpha as a single index of reliability, we also evaluated average inter-item correlations as recommended by Clark and Watson (1995), which should fall between .15 and .50 , as anything below .15 suggests being too broad of a construct while anything above .50 suggests redundancy.

In the second phase, inferential statistical analyses were conducted. First, multivariate analyses of variance (MANOVA) were used to test the relationships of care competencies with the sociodemographic variables. Considering the large sample size, a significance level of $p<.01$ was put forward (Kim 2015). Next, partial correlations and multiple linear regressions were applied to explore the relationships between care competencies and wellbeing, controlling for relevant demographic variables. Finally, two-way interaction effects were estimated using multiple regressions, to test the interaction of care dimensions in predicting adolescents' well-being. Mplus version 8.3 (Muthén and Muthén 1998-2017) was used for CFA and SPSS 24.0 was used for the descriptive and inferential analysis.

\section{Results}

\section{Factor Analysis of the CCQA}

KMO (0.79) and Barlett's test $\left(d f=630 ; \chi^{2}=4156.10\right.$; $p<.001$ ) indicated the sample was adequate and factor analysis was valid. The EFA was separately conducted for each dimension of care. Analysis of eigenvalues, scree plot and interpretability of the factors suggested a two-factor solution for each of the three care competencies. After rotation, all the positively-worded items loaded on the first factor and all the negatively-worded items on the second factor, identifying two latent constructs underlying each dimension of care: care competencies and care failures. The two retained factors explained $36.6 \%$ of the variance of receiving care items, $31.8 \%$ of the variance of self-care items and $33.8 \%$ of the variance of extending care items.

Based on the two first-order factors (care competencies and care failures) resulting from EFAs, a CFA with MLR estimation was performed to evaluate the fit of a two-factor model for each dimension of care separately. After stepwise removal of two items with poor factor loadings in each dimension of care $(<.30)$, the model fitted the data sufficiently for self-care: normed $\chi^{2}=2.12 ; \mathrm{CFI}=.91$; RMSEA $=.04 ; \mathrm{SRMR}=.04$. However, for receiving care and extending care scale, the model still did not fit the data adequately. Based on modification indices, the fit of these models was improved by allowing error correlations between items 3 and $8(r=.38)$ and 5 and 9 $(r=.23)$ of receiving care and items 25 and 26 of extending care $(r=.48)$, resulting in good fit for the models for receiving care: normed $\chi^{2}=2.97, \mathrm{CFI}=.93 ; \mathrm{RMSEA}=.05$; $\mathrm{SRMR}=.05$, and extending care: normed $\chi^{2}=2.03$; $\mathrm{CFI}=.95$; RMSEA $=.04$; SRMR $=.04$. Next, an overall 6factor CFA model was conducted on 30 items of the CCQA, based on the 2-factor models above. In this step, three additional error correlations (items $7 \& 4, r=-.18$, item $13 \& 14$, $r=.19$ and item $19 \& 20 r=.22$ ) were allowed based on modification indices for similarly worded items. As indicated in the top row of Table 2, this 6-factor model demonstrated good fit. Noticeably, as mentioned above, we decided to retain item 15 and $20(<.30)$ to guarantee the measurement of the behavioral facet of self-care.

Some alternative models were also evaluated via CFA. First, a higher-order latent variable model was studied to determine if relationships between the six factors could be explained by two overarching constructs: care competencies and care failures. This hierarchical model resulted in unsatisfactory fit compared to the previous model $\left(\Delta \chi^{2}=148.91\right.$, $p<.001 ; \Delta \mathrm{CFI}=.06)$. Second, based on the EFA-results showing a clear 2-factor structure (care competencies and care failures) in all three dimensions of care, a global two-factor model was estimated. However, as reflected in Table 2, compared to the 6-factor model, the model also did not fit the data 
Table 2 Fit of CFA Models of the CCQA

\begin{tabular}{lllll}
\hline Models & normed $\chi 2$ & CFI & RMSEA & SRMR \\
\hline Six factors & 1.69 & .90 & .03 & .05 \\
Six factors + two higher order factors & 2.06 & .84 & .04 & .06 \\
Two factors & 2.64 & .77 & .04 & .07 \\
Three factors & 2.62 & .75 & .05 & .08 \\
\hline
\end{tabular}

sufficiently well, $\Delta \chi^{2}=272.72, p<.001 ; \Delta \mathrm{CFI}=.13$. Third, another global model with three factors based on the variables rooted in the Mind and Life Institue (2014) framework of the care concept (receiving care, self-care and extending care) was tested. Similarly, this model did not fit the data adequately, $\Delta \chi^{2}=$ $347.73, p<.001 ; \Delta \mathrm{CFI}=.15$. In sum, comparison of all tested CFA models results in the conclusion that distinguishing between six factors within the CCQA best represents the data structure. The standardized loadings of this model are displayed in Table 3. Unstandardized latent factor scores from the 6-factor model were saved for further analyses.

Internal consistency, descriptives and correlations of the CCQA are reported in Table 4. Despite some of the alpha's being rather low, the mean inter-item correlation for each subscale fell within the recommended range. Most of the correlations between factors were meaningful and quite strong, mirroring convergent validity of the scale. However, we also observe a significant positive relationship between self-care competencies and self-care failures.

\section{Care Competencies and Sociodemographic Variables}

MANCOVA was applied with eight sociodemographic variables (i.e., age, gender, family structure, family size, rank in family, family income, location, and academic achievement) as independent variables, and the care dimensions as dependent variables. Significant multivariate effects based on Wilk's lambda were found for only two independent variables (i.e., gender and academic achievement). There was a strong connection between care competencies/failures and gender $\left(F(6,707)=8.93, p<.001, \eta^{2}=.07\right)$, with higher receiving care competencies $\left(F(1,712)=19.85, p<.001, \eta^{2}=.03, b=\right.$ $-.12)$, self-care competencies $(F(1,712)=34.57, p<.001$, $\left.\eta^{2}=.05, b=-.20\right)$, self-care failures $(F(1,712)=16.05$, $\left.p<.001, \eta^{2}=.02, b=-.21\right)$ and extending care competencies $\left(F(1,712)=28.94, p<.001, \eta^{2}=.04, b=-.24\right)$ in female compared to male adolescents, and with higher extending care failures in male adolescents $(F(1,712)=8.68, p<.01$, $\left.\eta^{2}=.01, b=.07\right)$.

In terms of academic achievement, there was a statistically significant difference in care competencies/failures based on academic achievement $\left(F(6,707)=4.01, p<.001, \eta^{2}=.03\right)$, indicating that those with good GPA had higher levels of self-care competencies $\left(F(1,712)=14.44, p<.001, \eta^{2}=.02\right.$, $b=.09)$; extending care competencies $(F(1,712)=8.72$, $\left.p<.01, \eta^{2}=.01, b=.09\right)$ and lower levels of extending care failures $\left(F(1,712)=8.50, p<.01, \eta^{2}=.01, b=-.05\right)$.

\section{Care Competencies and Well-Being of Adolescents}

In order to check whether control variables should be included in the correlation and regression analysis, a MANCOVA was run with the same eight sociodemographic variables as independent variables, and well-being indicators as dependent variables. Significant multivariate effects were only found for age $\left(F(3,710)=5.00, p<.01, \eta^{2}=.02\right)$ and family economic condition $\left(F(3,710)=7.07, p<.001 ; \eta^{2}=.03\right)$. Univariate results indicated that older adolescents experienced more emotional and behavioral difficulties $\left(F(1,712)=7.64, p<.01, \eta^{2}=.01\right.$, $b=.03)$ and perceived stress $(F(1,712)=11.63, p<.001$, $\eta^{2}=.02, b=.07$ ), compared to younger ones, and adolescents from richer families had higher life satisfaction than those from more poor ones $\left(F(1,712)=9.94, p<.01, \eta^{2}=.01\right.$, $b=.22$ ). Based on these results, we decided to control for age and family economic condition in subsequent correlation and hierarchical regression analyses.

Next, partial correlations revealed that all three dimensions of care competencies were positively related with life satisfaction. Receiving care and extending care competencies were significantly negatively correlated with behavioral and emotional difficulties. Unexpectedly, extending care competencies and self-care competencies were found to be positively but relatively weakly correlated with perceived stress. All three dimensions of care failures were negatively related with life satisfaction and were positively related with perceived stress and emotional and behavioral difficulties (Table 5).

Subsequent hierarchical linear regressions with age and family economic condition entered in Step 1 of the regression and care competencies/failures in Step 2, showed that care competencies/failures explained an additional $18 \%$ of variance in perceived stress $(F(6,727)=26.85, p<.001)$. As can be seen in Table 5, the single predictor of higher perceived stress was more self-care failure. Regarding behavioral and emotional difficulties, care competencies/failures explained an additional $24 \%$ of variance $(F(6,727)=39.45, p<.001)$. Receiving care competencies, self-care failures and extending care failures were significant predictors of behavioral and emotional difficulties, in the direction as expected. In terms of life satisfaction, care competencies/failures additionally explained $12 \%$ of variance $(F(6,725)=16.64, p<.001)$. 
Table 3 Factor Loadings of 6-factor CFA of the CCQA

Items

\begin{tabular}{|c|c|c|}
\hline iving & $\begin{array}{l}\text { Self- } \\
\text { care }\end{array}$ & $\begin{array}{l}\text { Extending } \\
\text { care }\end{array}$ \\
\hline $\mathrm{F}$ & $\mathrm{C} \quad \mathrm{F}$ & $\mathrm{C}$ \\
\hline
\end{tabular}

1. I am open to express what I think and feel so that others can understand my needs.

.37

2. I am happy when others share my joys and sorrows.

3. I know there is always someone there for me when I need comforting.

4. I am grateful and express my gratitude to the one who has helped me to overcome my difficulties.

.41

5. I feel comfortable to receive support from others when in need because receiving support is part of being human. .36

6. I do not want others to know my emotions and thoughts as well as my circumstances.

.62

.64

.48

.56

.54

10. When needing someone to help me to deal with a personal problem, I do not know who I can turn to.

11. I notice and am sensitive to the changes of my emotions

12. I try to understand the cause of negative emotions (sadness, anger, disappointment...)

13. I gently accept bad things happening to me because I see the difficulties as part of life that everyone goes through.

14. "Human is imperfect", so I do not get disappointed with some bad habits of mine; instead, I try to change them.

15. I make time for what I want to do.

16. I cannot identify my own emotions.

17. I pretend something has not happened in order to avoid thinking about my difficulties.

18. When failing or feeling very sad, I often withdraw and feel like the whole world abandons me.

19. When doing something wrong, I often criticize and hate myself.

20. I easily change my personal plans, when another person is in need.

21. I notice others' joys and sorrows, even if they don't say anything.

22. I try to put myself in others' shoes when they are in trouble in order to understand their needs

23. I feel happy when I see others happy.

24. I am touched when I see miserable and starving people.

25. I spend time helping people in need.

26. When others are suffering, I try my best to help them.

27. I tend to judge people rather than trying to understand them.

28. I feel envious when others get achievements and happiness in their life.

30. When I see someone in pain or difficulties, I walk away.

$C$, competencies; $F$, failures

However, none of the care competencies/failures appeared to be a unique predictor of life satisfaction.

\section{Interactions between Care Competencies/Failures Predicting Well-Being}

Three significant interactions were found out of 45 interactions tested. We used the simple slope plots by Dawson (2014) to interpret interaction effects. First, an interaction between self-care competencies and receiving care competencies emerged, predicting perceived stress in adolescents $(\beta=-.04, p<.01)$. Figure 1a shows that the positive relationship between self-care competencies and perceived stress was weaker if receiving care competencies were high. Second, the interaction between extending care competencies and receiving care competencies of adolescents was significant $(\beta=$ $-.05, p<.01)$. As displayed in Fig. 1b, adolescents with high extending care competencies but low receiving care competencies, experienced most stress. Moreover, only when receiving care competencies were low, high extending care competencies predicted more stress. Finally, the effect of receiving care competencies on perceived stress also depended on the level of extending care failures $(\beta=-.05, p<.01)$. As displayed in Fig. 1c, only adolescents with high receiving care competencies and high extending care failures, experienced more perceived stress. 
Table 4 Internal Consistencies, Descriptives and Correlations of the CCQA Subscales

\begin{tabular}{|c|c|c|c|c|c|c|c|c|c|}
\hline & $\alpha$ & Average $r_{\text {item,item }}$ & $M$ & $S D$ & 2. & 3. & 4. & 5. & 6. \\
\hline \multicolumn{10}{|l|}{ Receiving care } \\
\hline 1. competencies & .50 & .17 & 4.33 & 0.74 & $-.39 * * *$ & $.77 * * *$ & -.06 & $.73 * * *$ & $-.56 * * *$ \\
\hline 2. failures & .72 & .34 & 2.81 & 1.00 & & -.04 & $.12 * *$ & -.03 & $.41 * * *$ \\
\hline \multicolumn{10}{|l|}{ Self-care } \\
\hline 3. competencies & .49 & .16 & 4.10 & 0.81 & & & $.27 * *$ & $.86 * * *$ & $-.56 * * *$ \\
\hline 4. failures & .56 & .20 & 3.16 & 0.91 & & & & $-.12 * *$ & $.32 * * *$ \\
\hline \multicolumn{10}{|l|}{ Extending care } \\
\hline 5. competencies & .64 & .23 & 4.25 & 0.77 & & & & & $-.82 * * *$ \\
\hline 6. failures & .50 & .20 & 2.49 & 0.84 & & & & & \\
\hline
\end{tabular}

\section{Discussion}

Though care competencies are believed to increase well-being in adolescents (Mind and Life Institue 2014), empirical evidence is lacking due to unavailability of age-appropriate instruments. This inspired the development of the CCQA to assess different dimensions of care in adolescents. This helped studying the unique association between care competencies, sociodemographic characteristics, and well-being, as well as the interactions between care dimensions in predicting adolescents' well-being.

\section{Validation of the CCQA}

The findings from the EFA relatively unexpectedly revealed that items in each dimension of care did not cluster into three competency factors (cognition, affect, and behavior) as expected from Blömeke's competency model (Blömeke et al. 2015). Instead, the positively and negatively worded items fell apart in two factors underlying each dimension: care competencies and care failures. According to Neff (2003), it is not uncommon for negative and positive items in self-report measures to load on separate factors. Neff (2003) had the same experience when developing and validating The Self-Compassion Scale. Recently, the studies by Brenner et al. (2018) and Van der Gucht et al. (2017) confirm that the positive (i.e., self-kindness, common humanity, and mindfulness) and negative (i.e., self-judgment, isolation, and over-identification) components of self-compassion reflect two distinct constructs (self-kindness and self-coldness). Gibert's Social Mentality Theory (Gilbert 2005) also points out that compassionate ways of responding to suffering tap into parasympathetic nervous system activity, and uncompassionate ways of responding tap into the sympathetic nervous system, suggesting that care competencies and care failures should not be measured as a single factor. Care failures, therefore, may not be simply the absence of care competencies. Feeling competent in care and failing in care are two different experiences. For example, a person who does not feel happy when noticing others are happy (low extending care competency), does not necessarily feel envious when others get happiness in their life (high extending care failure); or a person who does not tend to easily change his personal plans because of others' plans (low self-care failure) does not necessarily make time for his hobbies (high self-care competency). Besides, an individual can exhibit both care competencies and care failures. For example, a person could be touched when seeing miserable and starving people but also sometimes could feel envious when others get achievements and happiness in their life.

Table 5 Correlations and Standardized Regression Coefficients among Care Competencies and Failures and Adolescents' Well-Being \& Prosocial Behavior in Adolescents

\begin{tabular}{|c|c|c|c|c|c|c|c|}
\hline & & \multicolumn{3}{|c|}{ Care Competencies } & \multicolumn{3}{|l|}{ Care Failures } \\
\hline & & Receiving care & Self-care & Extending care & Receiving care & Self-care & Extending care \\
\hline \multirow[t]{2}{*}{ SDQ Total Difficulties } & $r$ & $-.18 * * *$ & -.02 & $-.11 * *$ & $.42 * * *$ & $.46 * * *$ & $.31 * * *$ \\
\hline & $\beta$ & $-.21 *$ & -.08 & .29 & -.16 & $.47 * * *$ & $.30^{* *}$ \\
\hline \multirow[t]{2}{*}{ Perceived stress } & $r$ & .05 & $.19 * * *$ & $.11 * *$ & $.31 * * *$ & $.42 * * *$ & $.09 *$ \\
\hline & $\beta$ & .05 & .09 & -.10 & -.01 & $.43 * * *$ & -.06 \\
\hline \multirow[t]{2}{*}{ Life satisfaction } & $r$ & $.29 * * *$ & $.21 * * *$ & $.23 * * *$ & $-.25 * * *$ & $-.18 * * *$ & $-.25 * * *$ \\
\hline & $\beta$ & .04 & .09 & .22 & -.20 & -.11 & .12 \\
\hline
\end{tabular}

$* * * p<.001 ; * * p<.01 ; * p<.05$ 
Fig. 1 Interactions between care dimensions in the prediction of perceived stress a
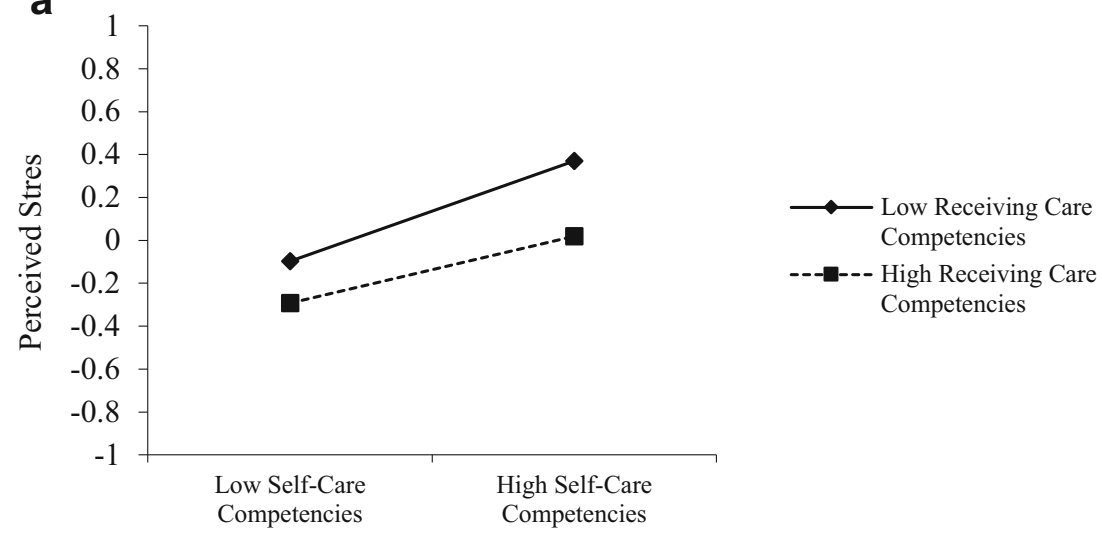

b
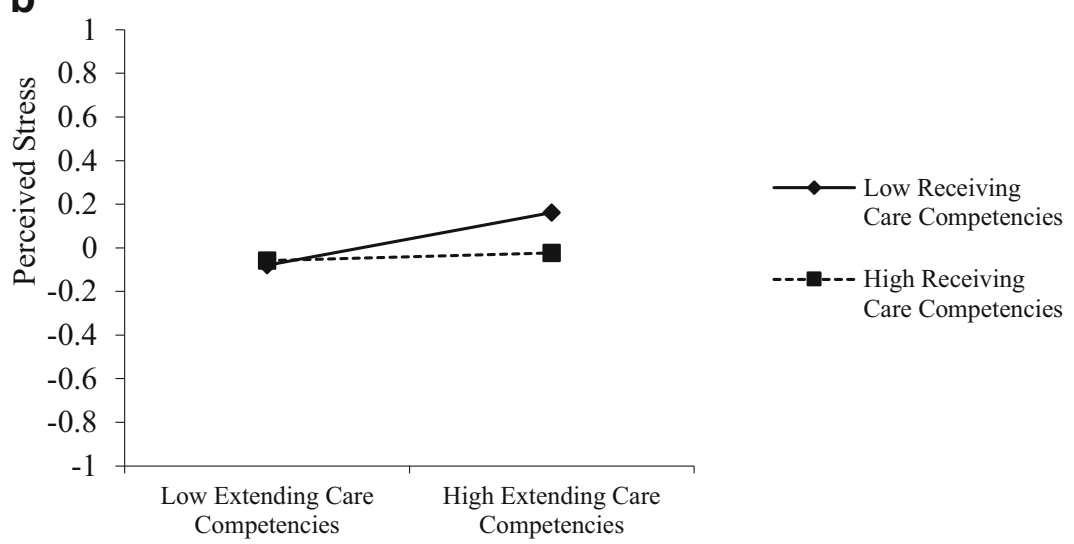

C

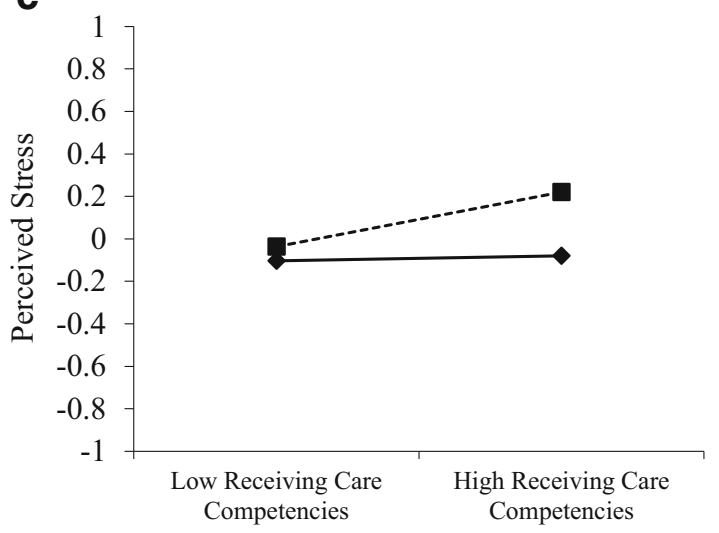


two distinct systems; adolescents can both feel competent in self-care and experience failure in self-care. This paradoxical finding, in fact, seems to reveal an ambivalent struggle inside some adolescents between self-coldness and self-kindness. Some adolescents seem to try to practice self-kindness at moments they tend to criticize and disappoint themselves (Brenner et al. 2018).

\section{Care Competencies and Sociodemographic Variables}

Out of eight sociodemographic characteristics, only gender and academic achievement were related to dimensions of care competencies and failures. As reported, girls possess higher levels of receiving care, self-care and extending care competencies and lower extending care failures, compared to boys. These results are consistent with previous findings indicating women have higher levels of care-seeking and care-giving than men (Hermanto and Zuroff 2016; López et al. 2018). Differences in extending care, self-care and receiving care between boys and girls are probably in large part due to different socialization processes, even nowadays and sure in Vietnam (Nguyen 2000), the country in which this study took place. For example, girls are handed dolls and baby carriages to play with (suggesting nurturing and caring behaviors) and boys are handed superheroes and toy soldiers (suggesting fighting, and protecting behaviors). As empathy is seen as a more "feminine" trait that is more acceptable for women, women may have learned to both communicate and recognize it more easily (Hertenstein and Keltner 2011). Noticeably, female adolescents also scored significantly higher in both self-competencies and self-care failures. Gender differences in self-care are not consistent in previous studies. Metaanalytic research suggests that women have slightly lower levels of self-compassion (Yarnell et al. 2015). However, Ayala et al. (2018) found out that men were more likely to report poorer self-care but women still experienced significantly more stress than men. On the one hand, these findings confirm again that self-care competencies and care failures are two different experiences. On the other hand, it seems to imply that female adolescents find self-care more challenging, compared to man. Females also reflect more self-blame and selfcriticism when coping with stressful events compared to men (Kelly et al. 2008). However, ironically, the fear that selfcompassion is a weakness prevents men from getting benefit from developing this skill (Yarnell et al. 2015).

Results revealed that adolescents with higher academic achievement also report higher receiving care, self-care and extending care competencies and lower levels of extending care failures. These findings support results from previous studies that students with adaptive social and emotional competencies are most likely to excel in school (e.g., Collie et al. 2018; McCormick et al. 2015). In general, our findings seem to suggest that future care cultivation programs should consider gender and academic achievement differences to set different priorities to participants.

\section{Care Competencies and Well-Being of Adolescents}

As expected, findings confirm that care competencies and failures and well-being are significantly related. The findings show a basic contribution of care competencies to well-being and a potential prediction of care failures to ill-being. All three dimensions of care failures were moderately or strongly associated with the three well-being indicators. In addition, noticeably, self-care failures are the strongest unique predictor of perceived stress and social-emotional difficulties. In contrast, the predictive power of care competencies in this present study was weak. Only receiving care competencies significantly predicted less emotional and behavioral problems. At first hand, the unexpected positive relationship between selfcare and extending care competencies and perceived stress seems to imply that high level of these two competencies is somewhat stressful. However, these relationships were very weak and did not stay when controlling for care failures in the regressions. Therefore, these findings do not support the paradox of giving care ( $\mathrm{Lu}$ and Argyle 1992) and unexpected side-effects of mindful self-awareness (Shapiro 1992).

Firstly, part of these findings may support the results of the study by Brenner et al. (2018) on an adult sample that selfcoldness was more strongly related to depressive symptoms than self-kindness. Secondly, these findings support the conclusion from Bal et al. (2003), Bluth and Blaton (2015), Bluth and Eisenlohr-Moul (2017), Edwards et al. (2014), Ferrari et al. (2019), Layous et al. (2012), and Pareek and Jain (2012) that the strongest determinants of life-satisfaction, positive mental health are practical social support, selfcompassion and care-giving practices; and from Stafford et al. (2015), Brenner et al. (2018) and Beaumont et al. (2016) that poor received social support, self-coldness and poorer compassion for others might lead to ill-being.

On the one hand, these findings imply that opening up to and cherishing the fact that other people care about them, helps adolescents to feel connected, needed, and included in the lives of others. Showing kindness, support and empathy for others helps them to strengthen their relationships with others and build new ones. Overall, both receiving care and extending care competencies can satisfy the need for relatedness by boosting social connection. In turn, a feeling of social connection to others might boost their sense of well-being. Research has shown that people who feel more connected to others reflect lower anxiety and depression rates (Seppala et al. 2013). Moreover, both receiving care and extending care competencies might also satisfy the need for competence of adolescents. Appropriate care from others can increase self- efficacy - an assurance that a person can achieve his desired goal (Akbarbegloo et al. 2015; Wang et al. 2015). Similarly, helping others will improve how adolescents see 
themselves and value their contribution to the lives of others. In other words, extending care may give adolescents a sense of purpose in life and a feeling of self-worth. Self-care may enhance adolescents' well-being because it also helps the need for competence to be fulfilled. By truly accepting themselves, being kind to themselves and by stopping criticizing themselves, adolescents tend to value themselves, which increases their self-efficacy.

On the other hand, the findings of this study also imply that the reluctance of adolescents to receive support from others and give support to others might limit their self-efficacy, their belongingness to others and prevent them from trusting to be cooperative sources of help, which in turn, decreases their well-being. Similarly, self-criticism and maladaptive perfectionism may put adolescents under pressure, which in turn leads to lower self-worth. These failures in receiving care, extending care and self-care, therefore, affect their well-being. Noticeably, self-care failures are the most important predictor of stress in adolescents. More focus should be put on the overcoming of failures in self-care, especially self-judgement in future care training and counseling programs.

\section{Interactions between Care Competencies/Failures in the Prediction of Well-Being}

As stated above, it might be the case that each dimension of care does not uniquely predict well-being, but that this relationship depends on the effect of other dimensions (Mind and Life Institue 2014). However, in this study, not much evidence for interaction between care dimensions was found. Only three interactions underscored the assumption that well-being depends on the ability to balance the different competencies of care. For example, the imbalance between giving care and receiving care seems to lead to more perceived stress. Adolescents with high extending care competencies but low receiving care competencies experienced most perceived stress; in contrast, adolescents with high receiving care competencies experience lower stress, regardless of their competency to extend care. These findings provide limited support to the conclusion from Cosley et al. (2010) that our ability to receive social support may be strengthened by the compassion for others, which may help us to adapt effectively to stress.

\section{Limitations and Directions for Future Research}

Several limitations of this study need to be acknowledged. First, the present study was entirely based on self-reports by adolescents, which might have inflated some of the findings, partly due to social desirable answering. Future research should include various data sources like questionnaires, observations, and structured interviews to reduce the impact of these biases.

Secondly, these findings are limited by the use of a crosssectional design. Though cross-sectional data do not prevent us from assessing associations among variables, they constrain our ability to draw strong conclusions and to make causal inferences with regard to the well-being of adolescents. Therefore, future research should implement experimental (intervention) and longitudinal designs.

Thirdly, although we selected valid questionnaires, the problem with unreliability of some scales may occur due to the fact that part of the data was gathered right after the biggest flood since 1999 in Vietnam. This particularly might have influenced answers on specific items regarding care competencies and wellbeing. Future research with the CCQA should re-evaluate reliability and validity in other samples, as well as with other types of reliability, such as test-retest reliability.

Next, since the study was limited to 14-17-year-old adolescents, caution is needed to build on these data when looking at youngsters in early adolescence (11-13 years). We look forward to involving a larger age-range in future research.

Lastly, we linked care competences to well being. This was done in view of a further validation of the care competence scale. As such, we did not develop an extensive model about the relationship between care and well-being. This is clearly an avenue for future longitudinal research that can start now because an adequate measure is available.

\section{Conclusion}

The results of this study suggest that the CCQA provides an appropriate and valid instrument for measuring care competencies in adolescents in educational contexts. Six factors of the care competencies scale were identified: competencies and failures in receiving, extending and self-care. In general, the findings support the assumption that adolescents' well-being depends on their ability and failure to receive care from others, to extend care to others, and to develop self-care, and also, their ability to balance these care dimensions. The former implies that our study contributes in a theoretical way to the literature by developing an integrated conceptualization of care and by putting forward empirical evidence. Also, our empirical results underpin the reliability and validity of an instrument in line with this new conceptualization. Our findings contribute to our understanding of the influences of care competences in adolescents; e.g., that overcoming care failures seems more important than building care competencies in adolescents. Lastly, we could demonstrate the interdependence of the three care dimensions and how they interact with well-being. These contributions help grounding the importance and content of future care-cultivation programs targeting adolescents.

Acknowledgements This research is supported by the VLIR-IUC Program Hue University (iuc.hueuni.edu.vn). We are grateful to the schools and students participating in this study. 


\section{Compliance with Ethical Standards}

Conflict of Interest No conflict of interest in whatever form exists related to this study, for none of the authors. Moreover this study was not submitted before nor is it under consideration for publication elsewhere.

Ethical Statement Ethical approval for this study was obtained from Institutional Ethical Committee of Hue University.

Informed Consent "Active informed consent was obtained (1) the director of the Education and Training Department of Hue City, (2) the concerned school authority in line with formal regulations, and (3) from the participating adolescents themselves. See the original used informed consent form for adolescents (in Vietnamese) on the supplementary document.

\section{References}

Akbarbegloo, M., Valizadeh, L., Zamanzadeh, V., \& Jabarzadeh, F. (2015). The relationship between self-efficacy and psychosocial care in adolescents with epilepsy. Epilepsy Research and Treatment, 2015, 1-7. https://doi.org/10.1155/2015/756849.

Bakar, A. A., \& Sidek, A. F. W. (2013). Well-being in adolescence: Fitting measurement model. International Journal of Social, Behavioral, Educational, Economic, Business and Industrial Engineering, 7, 1141-1144. https://doi.org/10.5281/zenodo.1072626.

Ayala, E. E., Winseman, J. S., Johnsen, R. D., \& Mason, H. R. C. (2018). U.S. medical students who engage in self-care report less stress and higher quality of life. BMC Medical Education, 18, 189. https://doi. org/10.1186/s12909-018-1296-x.

Bal, S., Crombez, G., van Oost, P., \& Debourdeaudhuij, I. (2003). The role of social support in well-being and coping with self-reported stressful events in adolescents. Child Abuse and Neglect, 27, 13771395. https://doi.org/10.1016/j.chiabu.2003.06.002.

Battistich, V., Solomon, D., Watson, M., \& Schaps, E. (1997). Caring school communities. Educational Psychologist, 32, 137-151. https://doi.org/10.1207/s15326985ep3203_1.

Baumgartner, H., \& Steenkamp, J. B. E. (2001). Response styles in marketing research: A cross national investigation. Journal of Marketing Research, 38, 143-156. https://doi.org/10.1509/jmkr.38. 2.143.18840.

Beaumont, E., Durkin, M., Hollins-Martin, C. J., \& Carson, J. (2016). Compassion for others, self-compassion, quality of life and mental well-being measures and their association with compassion fatigue and burnout in student midwives: A quantitative survey. Midwifery, 34, 239-244. https://doi.org/10.1016/j.midw.2015.11.002.

Bellet, P. S., \& Maloney, M. J. (1991). The importance of empathy as an interviewing skill in medicine. JAMA, 266, 1831-1832. https://doi. org/10.1001/jama.1991.03470130111039.

Birkeland, M. S., Melkevik, O., Holsen, I., \& Wold, B. (2012). Trajectories of global self-esteem development during adolescence. Journal of Adolescence, 35, 43-54. https://doi.org/10.1016/j. adolescence.2011.06.006.

Bluth, K., \& Blanton, P. W. (2015). The influence of self-compassion on emotional well-being among early and older adolescent males and females. The Journal of Positive Psychology, 10, 219-230. https:// doi.org/10.1080/17439760.2014.936967.

Bluth, K., \& Eisenlohr-Moul, T. A. (2017). Response to a mindful selfcompassion intervention in teens: A within-person association of mindfulness, self-compassion, and emotional well-being outcomes. Journal of Adolescence, 57, 108-118. https://doi.org/10.1016/j. adolescence.2017.04.001.
Blömeke, S., Gustafsson, J.-E., \& Shavelson, R. J. (2015). Beyond dichotomies: Competence viewed as a continuum. Zeitschrift für Psychologie, 223, 3-13. https://doi.org/10.1027/2151-2604/a000194.

Brenner, R. E., Vogel, D. L., Lannin, D. G., Engel, K. E., Seidman, A., \& Heath, P. J. (2018). Do self-compassion and self-coldness distinctly relate to distress and well-being? A theoretical model of self-relating. Journal of Counseling Psychology, 65, 346-357. https://doi. org/10.1037/cou0000257.

Brown, K. W., \& Ryan, R. M. (2003). The benefits of being present: Mindfulness and its role in psychological well-being. Journal of Personality and Social Psychology, 84, 822-848. https://doi.org/ 10.1037/0022-3514.84.4.822.

Burn, R. (2016). Psychological well-being [PDF file]. In N. A. Pachana (Eds.), Encyclopedia of geropsychology $(251,1)$. Springer, Singapore. Retrieved from https://link.springer.com/content/pdf/10. 1007\%2F978-981-287-080-3 251-1.pdf

Chang, W. (2008). Caring school community evaluation report (2007-2008) [PDF file]. Retrieved from web.sfusd.edu/ .../Caring\%20School\%20Community\%20Evaluation $\% 20$ Report\%2020.

Chen, F. F., Jing, Y., Hayes, A., \& Lee, J. M. (2012). Two concepts or two approaches? A bi-factor analysis of psychological and subjective well-being. Journal of Happiness Studies, 14, 1033-1068. https:// doi.org/10.1007/s10902-012-9367-x.

Clark, L. A., \& Watson, D. (1995). Constructing validity: Basic issues in objective scale development. Psychological Assessment, 7, 309 319. https://doi.org/10.1037/1040-3590.7.3.309.

Cohen, S., \& Williamson, G. (1988). Perceived stress in a probability sample of the United States. In S. Spacapan \& S. Oskamp (Eds.), The social psychology of health: Claremont symposium on applied social psychology (pp. 31-67). Newbury Park: Sage.

Collie, R. J., Martin, A. J., Nassar, N., \& Roberts, C. L. (2018). Social and emotional behavioral profiles in kindergarten: A population-based latent profile analysis of links to socio-educational characteristics and later achievement. Journal of Educational Psychology, 111, 170-187. https://doi.org/10.1037/edu0000262.

Cosley, B. J., McCoy, S. K., Saslow, L. R., \& Epel, E. S. (2010). Is compassion for others stress buffering? Consequences of compassion and social support for physiological reactivity to stress. Journal of Experimental Social Psychology, 46, 816-823. https://doi.org/10. 1016/j.jesp.2010.04.008.

Cronbach, L. J. (1951). Coefficient alpha and the internal structure of tests. Psychometrika, 16, 297-334. https://doi.org/10.1007/ BF02310555.

Dawson, J. F. (2014). Moderation in management research: What, why, when and how. Journal of Business and Psychology, 29, 1-19. https://doi.org/10.1007/s10869-013-9308-7.

Diener, E., Emmons, R. A., Larsen, R. J., \& Griffin, S. (1985). The satisfaction with life scale. Journal of Personality Assessment, 49, 71-75. https://doi.org/10.1207/s15327752jpa4901_13.

Danielsen, A. G., Samdal, O., Hetland, J., \& Wold, B. (2009). Schoolrelated social support and students' perceived life satisfaction. The Journal of Educational Research, 102, 303-320. https://doi.org/10. 3200/JOER.102.4.303-320.

Edwards, M., Adams, E. M., Waldo, M., Hadfield, O. D., \& Biegel, G. M. (2014). Effects of a mindfulness group on Latino adolescent students: Examining levels of perceived stress, mindfulness, self-compassion, and psychological symptoms. The Journal for Specialists in Group Work, 39, 145-163. https://doi.org/10.1080/01933922.2014.891683.

Enders, C. K. (2001). The impact of nonnormality on full information maximum-likelihood estimation for structural equation models with missing data. Psychological Methods, 6, 352-370. https://doi.org/ 10.1037/1082-989X.6.4.352.

Ferrari, M., Hunt, C., Harrysunker, A., Abbott, M. J., \& Einstein, D. A. (2019). Self-compassion interventions and psychosocial outcomes: 
A meta-analysis of RCTs. Mindfulness., 10, 1455-1473. https://doi. org/10.1007/s12671-019-01134-6.

Gastmans, C. (2006). The care perspective in healthcare ethics. In A. J. Davis, V. Tschudin, \& L. de Raeve (Eds.), Essentials of teaching and learning in nursing ethics (pp. 135-148). London: Livingstone.

Gilbert, P., Catarino, F., Duarte, C., Matos, M., Kolts, R., Stubbs, J. ... \& Basran, J. (2017). The development of compassionate engagement and action scales for self and others. Journal of Compassionate Health Care, 4, 1-24, doi: https://doi.org/10.1186/s40639-0170033-3.

Gilbert, P. (2005). Compassion: Conceptualizations, research and use in psychotherapy. London: Brunner-Routledge.

Goodman, A., \& Goodman, R. (2012). Strengths and difficulties questionnaire scores and mental health in looked after children. The British Journal of Psychiatry, 200, 426-433. https://doi.org/10. 1192/bjp.bp.111.104380.

Goodman, R. (1997). The strengths and difficulties questionnaire: A research note. Journal of Child Psychology Psychiatry, 38, 581-586. https://doi.org/10.1111/j.1469-7610.1997.tb01545.x.

Grenville-Cleave, B. (2012). Introducing positive psychology: A practical guide. London: Icon Books.

Hamington, M., \& Sander-Staudt, M. (2011). Applying care ethics to business. New York: Springer.

Held, V. (2006). Feminist moral inquiry and the feminist future. In V. Held (Ed.), Justice and care (pp. 153-176). Boulder, CO: Westview Press.

Hermanto, N., \& Zuroff, D. C. (2016). The social mentality theory of selfcompassion and self-reassurance: The interactive effect of careseeking and caregiving. The Journal of Social Psychology, 156, 523-535. https://doi.org/10.1080/00224545.2015.1135779.

Hermanto, N., Zuroff, D. C., Kopala-Sibley, D. C., Kelly, A. C., Matos, M., Gilbert, P., et al. (2016). Ability to receive compassion from others buffers the depressogenic effect of self-criticism: A crosscultural multi-study analysis. Personality and Individual Differences, 98, 324-332. https://doi.org/10.1016/j.paid.2016.04. 055 .

Hertenstein, M. J., \& Keltner, D. (2011). Gender and the communication of emotion via touch. Sex Roles, 64, 70-80. https://doi.org/10.1007/ s11199-010-9842-y.

Hu, L., \& Bentler, P. (1999). Cutoff criteria for fit indices in covariance structure analysis: Conventional criteria versus new alternatives. Structural Equation Modeling, 6, 1-55. https://doi.org/10.1080/ 10705519909540118.

Jazaieri, H., Mcgonigal, K., Lee, I., Jinpa, T., Doty, J. R., Gross, J. J. .. \& \& Goldin, P. (2017). Altering the trajectory of affect and affect regulation: The impact of compassion training. Mindfulness, 9, 283-293. doi: https://doi.org/10.1007/s12671-017-0773-3.

Kelly, M. M., Tyrka, A. R., Price, L. H., \& Carpenter, L. L. (2008). Sex differences in the use of coping strategies: Predictors of anxiety and depressive symptoms. Depression and Anxiety, 25, 839-846. https:// doi.org/10.1002/da.20341.

Kessler, R. C., Berglund, P. A., Demler, O., Jin, R., \& Walters, E. E. (2005). Lifetime prevalence and age-of-onset distributions of DSM-IV disorders in the National Comorbidity Survey Replication (NCS-R). Archives of General Psychiatry, 62, 593602. https://doi.org/10.1001/archpsyc.62.6.593.

Kim, J. (2015). How to choose the level of significance: A pedagogical note. Retrieved from mpra.ub.uni-muenchen.de/66373/

Kline, R. B. (2011). Principles and practice of structural equation modeling. New York: Guilford Press.

Layden, R., Shale, E. (2012). What teachers need to know about social and emotional development. Camberwell, VIC: ACER.

Layous, K., Nelson, K. S., Oberle, E., Schoner-Reichl, K. A., \& Lyubomirsky, S. (2012). Kindness counts: Prompting prosocial behavior in preadolescents boosts peer acceptance and well-being.
PLoS One, 7, e51380. https://doi.org/10.1371/journal.pone. 0051380.

Little, R. J. A. (1988). A test of missing completely at random for multivariate data with missing values. Journal of the American Statistical Association, 83, 1198-1202. https://doi.org/10.1080/ 01621459.1988 .10478722$.

López, A., Sanderman, R., Ranchor, A. V., \& Schroevers, M. J. (2018). Compassion for Others and Self-Compassion: Levels, Correlates, and Relationship with Psychological Well-being. Mindfulness, 9, 325-331. https://doi.org/10.1007/s12671-017-0777-z.

Lu, L., \& Argyle, M. (1992). Receiving and giving support: Effects on relationships and well-being. Counselling Psychology Quarterly, 5, 123-133. https://doi.org/10.1080/09515079208254456.

McCormick, M. P., Cappella, E., O'Connor, E. E., \& McClowry, S. (2015). Social-emotional learning and academic achievement: Using causal methods to explore classroom-level mechanisms. Applied Psychology Teaching and Learning, 1, 1-26. https://doi. org/10.1177/2332858415603959.

Mind and Life Institute. (2014). A call to care: Teacher's professional development guide. Version 1. Virginia: Mind and Life Institute.

Mind and Life Institue. (2014). EEST planning year final report. Virginia: Mind and Life Institute.

Morse, J. M., Solberg, S. M., Neander, W. L., Bottorff, J. L., \& Johnson, J. L. (1990). Concepts of caring and caring as a concept. Advances in Nursing Science, 13, 1-14. https://doi.org/10.1097/00012272199009000-00002.

Muthén, L. K., \& Muthén, B. O. (1998-2017). Mplus User's Guide (8th ed.). Los Angeles: Muthén \& Muthén.

Neff, K. D. (2003). Development and validation of a scale to measure self-compassion. Self and Identity, 2, 223-250. https://doi.org/10. 1080/15298860309027.

Neff, K. D., \& McGehee, P. (2010). Self-compassion and psychological resilience among adolescents and young adults. Self and Identity, 9, 225-240. https://doi.org/10.1080/15298860902979307.

Nguyen, P. C. T., Beyers, W., Valcke, M. (2019). What is care? Towards an integrated definition. Unpublished manuscript. Ghent University, Belgium.

Nguyen, P. C. T., Nguyen, T. T. H. (2012). Mối quan hệ giữa stress và sự hài lòng của cuộc sống của sinh viên Trường Đại học $\mathrm{Y}$ Dược-Đại học Huế [The relationship between stress and life satisfaction among medical students of Pharmacy and Medicine College-Hue University]. Proceedings of the 3rd International Conference of School Psychology: Developing models and practical skills for school psychology, 142-157, Ho Chi Minh University of Education Publishing House.

Nguyen, X. N. (2000). Quá trình xã hội hóa về giới ở trẻ em [The socialization process of gender in children]. Ho Chi Minh Open University Publishing House.

Noddings, N. (1984). Caring: A feminine approach to ethics and moral education. Berkeley: University of California Press.

Noddings, N. (2004). Happiness and education (2nd ed.). New York: Cambridge University Press.

Pareek, S., \& Jain, M. (2012). Subjective well-being in relation to altruism and forgiveness among school going adolescents. International Journal of Psychology and Behavioral Sciences, 2, 138-141. https:// doi.org/10.5923/j.jpbs.20120205.02.

Podsakoff, P. M., MacKenzie, S. B., Lee, J. Y., \& Podsakoff, N. P. (2003). Common method biases in behavioral research: A critical review of the literature and recommended remedies. Journal of Applied Psychology, 88, 879-903. https://doi.org/10.1037/0021-9010.88.5. 879.

Ryff, C. D., Dienberg Love, G., Urry, H. L., Muller, D., Rosenkranz, M. A., Friedman, E. M., Davidson, R. J., \& Singer, B. (2006). Psychological well-being and ill-being: Do they have distinct or mirrored biological correlates? Psychotherapy and Psychosomatics, 75, 85-95. https://doi.org/10.1159/000090892. 
Ryan, R., \& Deci, E. (2001). On happiness and human potentials: A review of research on hedonic and eudaimonic well-being. Annual Review of Psychology, 52, 141-166. https://doi.org/10.1146/ annurev.psych.52.1.141.

Sakofsky, M. J. (2009). The impact of empathy skills training on middle school children (master's thesis). The College at Brockport, State University of New York, USA. Retrieved from http:// digitalcommons.brockport.edu/edc_theses/94

Schultze-Krumbholz, A., Schultze, M., Zagorscak, P., Wölfer, R., \& Scheithauer, H. (2016). Feeling cybervictims' pain-the effect of empathy training on cyberbullying. Aggressive Behavior, 42, 147-156. https://doi.org/10.1002/ab.21613.

Seppala, E., Rossomando, T., \& Doty, J. R. (2013). Social connection and compassion: Important predictors of health and well-being. Social Research: An International Quarterly, 80, 411-430. https://doi.org/ 10.1353/sor.2013.0027.

Shapiro, D.H. (1992). Adverse effects of meditation: A preliminary investigation of long-term meditators, International Journal of Psychosomatics, 39, 62-67. Retrieved from http://deanehshapirojr. org/wp-content/uploads/2016/10/Adverse-Effect-of-Meditation.pdf

Sourander, A., Multimäki, P., Santalahti, P., Parkkola, K., Haavisto, A., Helenius, H. ... \& Almqvist, F. (2004). Mental health service use among 18-year old boys: A prospective 10 year follow-up study. Journal of the American Academy of Child \& Adolescent Psychiatry, 43, 1150-1158. doi: https://doi.org/10.1097/01.chi. 0000134493.88549.e2.

Stafford, M., Kuk, D. L., Gale, C. R., Mishra, G., \& Richards, M. (2015). Parent-child relationships and offspring's positive mental wellbeing from adolescence to early older age. The Journal of Positive Psychology, 11, 326-337. https://doi.org/10.1080/17439760.2015. 1081971.

Thomas, C. (1993). De-constructing concepts of care. Sociology, 27, 649-669. https://doi.org/10.1177/0038038593027004006.
Tran, T. (2006). Nghiên cứu dịch tễ học về rối loạn tâm thần và mô hình chăm sóc sức khỏe tinh thần dựa vào cộng đồng [Epidemiology of mental disorders and the model of community-based mental health care]. The Proceeding of Conference on Mental Heath Care, 157168, Association of Vietnamese Psychology and Education, Hanoi, Vietnam.

Tronto, J. (1993). Moral boundaries: A political argument for an ethic of care. New York: Routledge.

Van der Gucht, K., Takano, K., Raes, F., \& Kuppens, P. (2017). Processes of change in a school-based mindfulness programme: Cognitive reactivity and self-coldness as mediators. Cognitive Emotion, 31, 1-8. https://doi.org/10.1080/02699931.2017.1310716.

Vaziri, S., Lotfi Azimi, A. (2012). The effect of empathy training in decreasing adolescents' aggression. Developmental Psychology (Journal of Iranian Psychologists), 8, 167-175. Doi: https://www. sid.ir/En/Journal/ViewPaper. Aspx?ID=272815.

Wang, C.-M., Qu, H.-Y., \& Xu, H.-M. (2015). Relationship between social support and self-efficacy in women psychiatrists. Chinese Nursing Research, 2, 103-106. https://doi.org/10.1016/j.cnre.2015. 10.002 .

WHO (2016). Adolescents' mental well-being-Fact sheet [PDF file]. Retrieved from www.euro.who.int/_data/assets/pdf_file/.../HBSCNo.7 factsheet_Well-being.pdf?

WHO (2019). Maternal, newborn, child and adolescent health: Why invest in adolescents' health? Retrieved from https://www.who. int/maternal_child_adolescent/topics/adolescence/why-invest/en/

Yarnell, L. M., Stafford, R., Neff, K. D., Reilly, E., Knox, M. C., \& Mullarkey, M. (2015). Meta-analysis of gender differences in selfcompassion. Self and Identity, 14, 499-520. https://doi.org/10.1080/ 15298868.2015.1029966.

Publisher's Note Springer Nature remains neutral with regard to jurisdictional claims in published maps and institutional affiliations. 